\title{
A Study on $i$-Fashion 3D Avatar's Consumer satisfaction \& Comparison of 3D and Direct Masurement - Based of Domestic University Students
}

\author{
Eunhee Choi ${ }^{1)}$ and Wolhee $\mathrm{Do}^{2) \dagger}$ \\ ${ }^{1)}$ Dept. of clothing and Textiles, Chonnam National University; Gwangju, Korea \\ ${ }^{2)}$ Dept. of Clothing and Textiles/Research Institute of Human Ecology, Chonnam National University; Gwangju, Korea
}

\begin{abstract}
This research is to understand customer satisfaction with virtual fitting based on a 3D body scanner and avatars as well as differences between avatars and the 'real me'. To this end, this research examined Korean college students to facilitate 3D body scanning, avatar generation and surveys. The author used 3D body scan data with direct measurements to identify differences between the 3D body scan data-based 'my avatar' and 'real me' in the virtual dress fitting system. The survey results on 'the level of customer awareness on 3D body scanner' found that the majority of both genders did not know about it and indicated a lower usability to incorporate IT technology into the fashion industry. The question in the 3D body scanning and avatar found an affirmative attitude. Satisfaction levels on the 3D avatars' similarity with 'own body' and garment fitting were positive and indicated a need for further technological improvements to express the avatars identical to customers' own body. More research is necessary for the accuracy of sizes for 3D body scanning that measure body sizes while wearing clothes. Avatars based on such datamay be less similar to 'own body' and cause customer dissatisfaction. Thus, further technology development is required to narrow gaps using data to make avatars that provide more accurate virtual fitting simulation services to customers.
\end{abstract}

Key words : 3D body scanner, virtual try-on, avatar, virtual garment fitting

\section{Introduction}

The 3D scanning technology has been rapidly developed and applied to a variety of industries in a high speedy way (Choi \& Do, 2014). There are many different devices that can be called 3D scanners. Any device that measures the physical world using lasers, lights or x-rays and generates dense point clouds or polygon meshes can be considered a 3D scanner. The common uniting factor of all these devices is that they capture the geometry of physical objects with hundreds of thousands or millions of measurements. The most common applications for 3D scanning are reverse engineering, inspection and digital archiving or 3D printing (" $3 \mathrm{D}$ scanners", 2014).

3D scanning is a fast and accurate method of putting physical measurements of an object onto the computer on an organized manner, resulting in what is commonly called 3D scan data. Typically the $3 \mathrm{D}$ scan data is represented with a scale digital model or a $3 \mathrm{D}$ graphical rendering. Once the scan data is on the computer, all of the dimensions of the physical object can be taken, such as length, width, height, volume, feature size, feature location, surface area, etc. 3D scan data is often used as a bridge between physical

$\uparrow$ Corresponding author; Wolhee Do

Tel. +82-62-530-1346, Fax. +82-62-530-1349

E-mail: whdo@chonnam.ac.kr objects and modern manufacturing. This is achieved by converting the data into computer-aided design (CAD) models, using it to compare against the "as-designed" ideal of the part, or using it in the seemingly infinite number of computer-aided engineering (CAE) tools available ("3D scanning technical information", 2012).

Body scanners will play a critical role in mass customization because they enable retailers to rapidly collect $3 \mathrm{D}$ data for each consumer. Computer software can then analyze the high-resolution images of the body to extract precise, standardized tailoring measurements. In conjunction with advanced design and production processes, body scanners will thus allow consumers to benefit from a modern form of custom tailoring and automated size selection. Traditional mass-produced clothing will also be improved as a result of body scan technology. Industry and academic researches are using large amounts of anthropometric (body measurement) data captured by body scanners to adjust the sizing systems of ready-to-wear clothing lines so that everyone in the target population is better fitted ("About the body scanner", 2011).

Park and Kim (2004) predicted about the future direction of the digital textile product market, saying that it will be the foundational base of clothing orders and lead an era of MTM-type clothing system, and increase the utilization of 3D and virtual space application system. In 2014, these market conditions have been already real- 
ized as they did. In addition, Lim (2012) studied about the utilization of virtual try on simulation and consumers' preference in apparel online shopping. As a result, she analyzed that the consumers' awareness of apparel shopping using virtual try-on was still in low. So, it required further active research and technology development of virtual try-on simulation using digital technologies in order to increase the consumers' satisfaction on their fitness of wearing size of the clothing item purchased via online shopping. Throughout Do (2010)'s study on 'The comparison of user preference on domestic versus a foreign 3D virtual try-on system', she analyzed consumers' preferences about the virtual avatar and virtual try-on images using the sample of 20 female college students. The result revealed that both domestic and foreign 3D virtual tryon systems are all evaluated to be satisfied by the sample. And she predicted that $3 \mathrm{D}$ virtual try-on system will continue to expand into internet clothing market.

$3 \mathrm{D}$ virtual fitting technology is commercialized which produces an avatar based on 3D body scan in offline stores and wears any desired cloth to the avatar modeled after a customer. The cuttingedge IT technology helps customers choose clothes freely without actually wearing them. Although the 3D technique was introduced and applied well in clothing industry, it still remains to be difficult for general consumers to use at easy.

Therefore, the study examines their perception of 3D body scanning \& avatar and satisfaction with the avatar with the participants who actually experienced in the work of creating 3D body scanning and avatar. The technology also compares the 3D body scan data of a fashion clothes customer and their actual measurements so that the customer can see if a certain clothes fits their well just by looking at the avatar. By doing to, reference data will be established to reduce inconvenience in using $3 \mathrm{D}$ body scan data.

\section{Method}

\subsection{Subjects}

This study was conducted from March to April, 2014, 3D body scanning, survey and direct measurement. This study surveyed the total 213, representing the distribution of 43 male, 170 women (Table 1). The subjects' average age is 22.2 years old; male 22.6 years old and female 22.1 years old in their twenties. The 151 sub-

Table 1. Major of the survey subjects

unit: $n(\%)$

\begin{tabular}{cccc}
\hline & Male & Female & Total \\
\hline Clothing \& textiles & $28(65)$ & $123(72)$ & $151(71)$ \\
etc. & $15(35)$ & $47(28)$ & $62(29)$ \\
Total & $43(20)$ & $170(80)$ & $213(100)$ \\
\hline
\end{tabular}

Table 2. Participants of 3D body scanning and direct measurements unit: $\mathrm{n}(\%)$

\begin{tabular}{cccc}
\hline & Male & Female & Total \\
\hline 3D body scanning & $44(21)$ & $168(79)$ & $212(100)$ \\
Direct measurements & $6(12)$ & $45(88)$ & $51(100)$ \\
\hline
\end{tabular}

jects are majored in 'Clothing \& Textiles (male 28, female 123)' and the other 62 are majored in Others (male 15, female 47).

$3 \mathrm{D}$ body scanning participants were total 212 , representing the distribution of 44 male, 168 female. Direct measurements participants were total 51, 6 male, 45 female (Table 2).

\subsection{Survey contents}

This research investigated college students to perform the 3D body scanner-based measurement, their avatar generation and virtual fitting. The research participants then were surveyed to collect their responses. This research survey was structured by appropriately modifying the preceding studies by Yoon (2011) and Pack (2006) for this research purposes. The survey has 35 items in total including 4 inquiry items on general information; 1 on the perception of 3D body scanner; 18 on usability of 3D body scanning $\&$ avatar; and 12 on the satisfaction of 3D body scanning experience $\&$ adaptedness of avatar vs real me. The 5-pointed likert scale was used (Table 3).

The survey details are as follows. Firstly, 'The area of usability of 3D body scanning \& avatar' was consisted of items on fashion coordination system, 3D avatar application, 3D body scanning process and 3D body scanning service. 'The fashion coordination system' is about physical appearance of information, exact dimensions of information, convenience of measuring the dressed state, variety of styling \& coordination of information, etc. 'The 3D avatar application' is to ask about the usefulness in online and offline shopping and in product purchase as well as users' knowledge of how to use their avatars. 'The 3D body scanning process' asks if scanning experience is interesting, convenient and appropriate, how much they would like to recommend the system and body measurement appropriateness. 'The 3D body scanning service' includes questions on the accuracy of size, adaptedness of avatar, variety of coordination and convenience of shopping. Next, 'The adaptedness of avatar vs real me' is about the similarity of the general image of avatar with my own appearances and virtual dress fitting satisfaction as well as the size accuracy of each part of body in the avatar with myself.

\subsection{Measurement method \& device}

2.3.1. Measurement method 
Table 3. Classification of survey contents

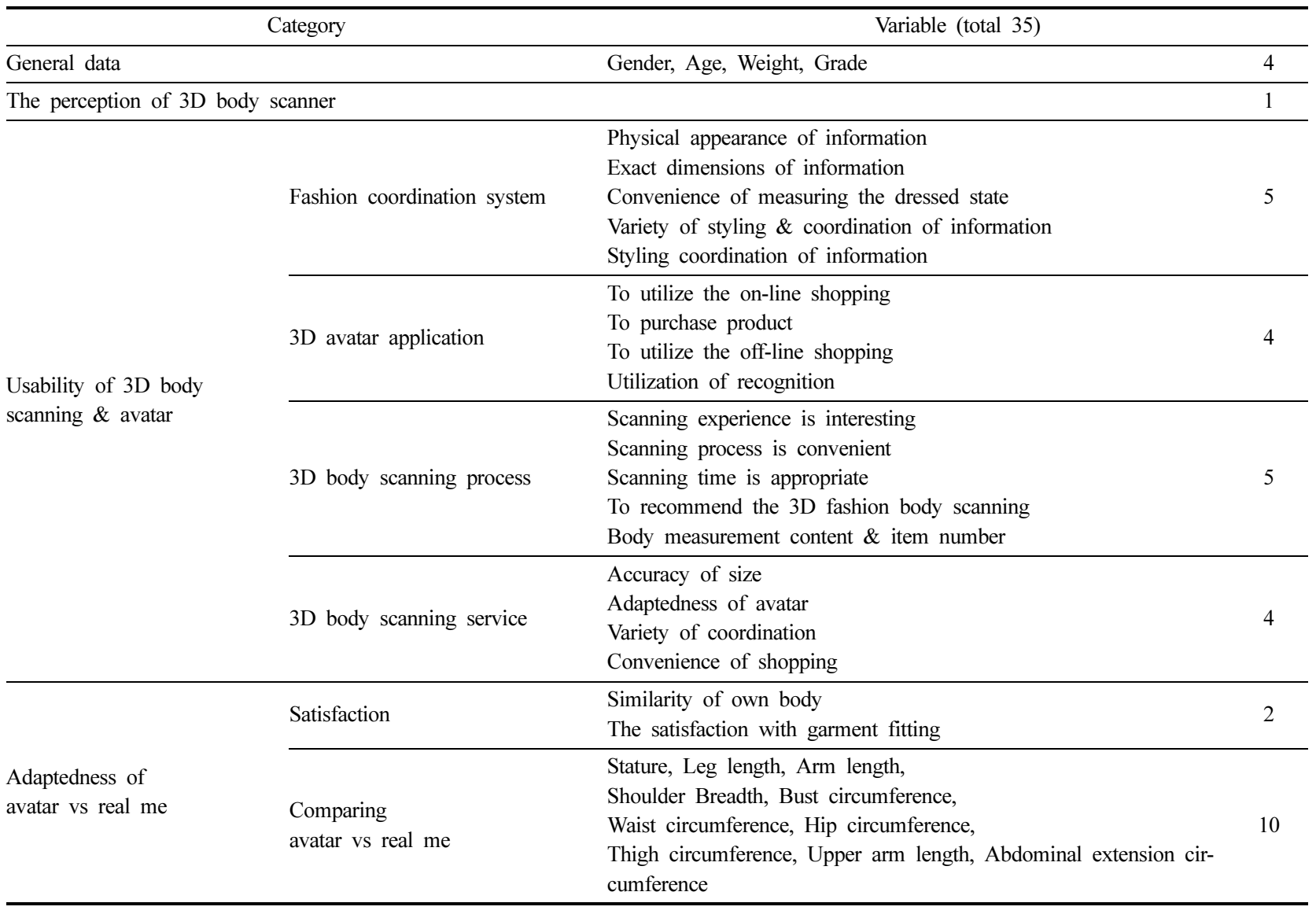

The study implemented 3D body scanning and creation 3D virtual avatar, select clothes on the display monitor and then experimented the 3D virtual garment fitting, virtual coordination, by using the $3 \mathrm{D}$ body measurement scanning system. In order to obtain optimal scanning data and image, the subject is asked to adopt a specified posture in the thinnest outfit without a heavy coat, a jumper, a jacket, clothes of metal decoration and metal accessory. Arms are kept apart from the torso to facilitate body data, participants are requested to hold their breaths while scanning to minimize movements.

As the 3D body scanner of the study, it used a vehicle type caravan system which was located in Chonnam National University College of Human Ecology. It measured the dressed state and the average time of 3D body scanner measuring time is about $30 \mathrm{sec}-$ onds. And about 15 minutes outside for scanning preparation to avatar creation and virtual fitting results were taken.

The participants were directly measured by using Martin instrument to measure the same measurement items used in the 3D body scanner. The measurement was performed for 3 rounds to gain the average for the research.

\subsubsection{D Measurement device}

The 3D whole-body scanner based on millimetric wave sensors used the characteristic that radio frequency moves through lowdensity objects (clothes, etc.) to measure human body 3D shape and sizes with a cloth on. The device automatically recognizes baseline points of human body for automatic measurement of each desired body part. The millimeteric wave complies with the FCC regulation and harmless to human body. Also, compared to existing scanners that require people to take off their clothes, the product enhances easy access to customers and convenience. The 3D body scanner MMW type used in this research was developed by the $i$ Fashion Technology Center in Fig. 1.

Key specifications of the human body measurement scanning system are in Table 4. Standard size of $\mathrm{H} 2,420 \times \mathrm{D} 2,200 \mathrm{~mm}$, frequency range 9 18 GHz, electric radio wave power $1 \sim 10 \mathrm{~mW}$ (harmless to human body), permeability (thickness of clothes) $2 \mathrm{~m}$, measurement volume of data 200,000pt, measurement distance $300 \sim 600 \mathrm{~m}$, scan time $30 \mathrm{sec}$ fewer (except processing time), accuracy $\pm 10 \mathrm{~mm}$ fewer(on the basis of calibration block), and device formation $3 \mathrm{D}$ body scanner $\mathrm{H} / \mathrm{W}$ system control PC \& operating 
Table 4. Key specifications of 3D body scanner MMW type

\begin{tabular}{ll}
\hline Items & Specification \\
\hline Size & $\mathrm{H} 2,420 \times \mathrm{D} 2,300(\mathrm{~mm})$ \\
Frequency range & $9 \sim 18 \mathrm{GHz}$ \\
Electric radio wave power & $1 \sim 10 \mathrm{~mW}$ (be harmless to humans) \\
Permeability (thickness of clothes) & FCC compliance regulation \\
Measurement volume of data & $2 \mathrm{~mm}$ \\
Measurement distance & $200,000 \mathrm{pt}$. \\
Accuracy & $300 \sim 600 \mathrm{~mm}$ \\
Scan time & $\pm 10 \mathrm{~mm}$ fewer(on the basis of calibration block) \\
Device formation & 30 sec fewer (except processing time) \\
\hline
\end{tabular}

The research used device of ' $i$-Fashion biz center for constructing strong point of 3D body scanning system' structured in support of technology fees by the MOTIE in 2012 .

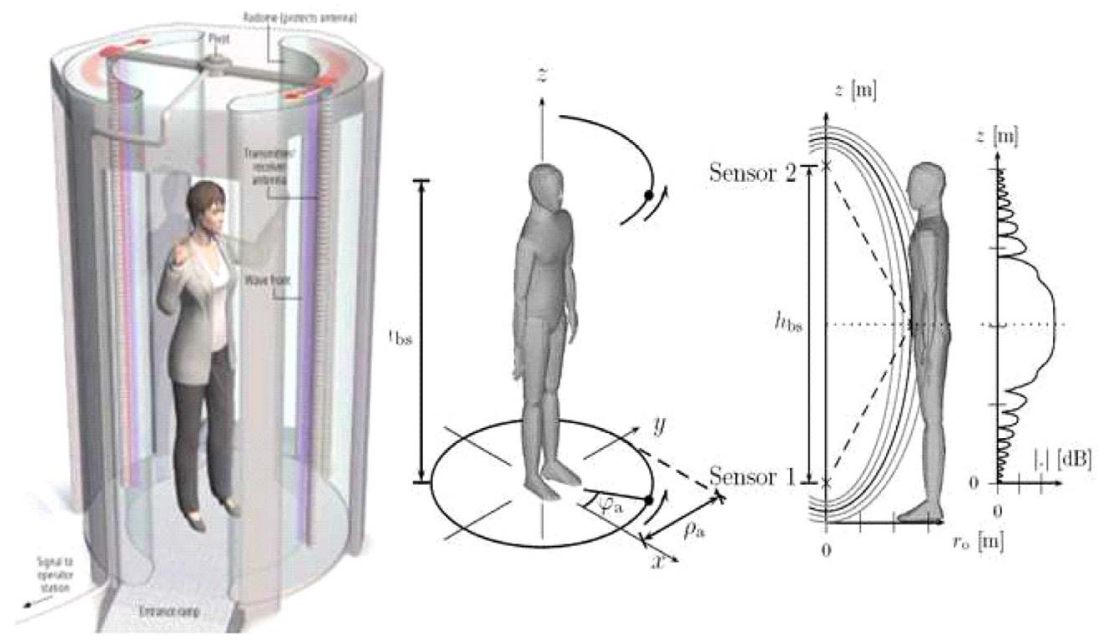

Fig. 1. 3D body scanner MMW type System of ' $i$-Fashion Biz Center'.

system $\mathrm{S} / \mathrm{W}$.

\subsection{D Measurement items and Methods of analysis}

3D body scanning measured 9 items (stature, leg length, arm length, shoulder breadth, bust circumference, waist circumference, hip circumference, thigh circumference, abdominal extension circumference).

The collected data were analyzed with descriptive statistics, $t$ test of survey data, $\mathrm{t}$-test of measurement data, and a chi-square to compare with gender using the SPSS 20.0.

\section{Results \& Discussion}

\subsection{Survey}

The survey results were as follows.
Firstly, about the question regarding the perception of 3D body scanner, the respondents reported 'do not recognize' with 52.1\% (111 persons) of all participants, $53.5 \%$ (23 persons) of male students, $51.8 \%$ (88 persons) of female students. Therefore, the result indicated that more than half of the subjects do not know it, the sur-

Table 5. Perception about 3D body scanner depending on the gender and major unit: $\mathrm{n}(\%)$

\begin{tabular}{|c|c|c|c|c|}
\hline & & Recognize & $\begin{array}{c}\text { Do not } \\
\text { recognize }\end{array}$ & $\chi^{2}$ \\
\hline \multirow{2}{*}{ Gender } & Male & $20(46.5)$ & $23(53.5)$ & \multirow{2}{*}{.041} \\
\hline & Female & $82(48.2)$ & $88(51.8)$ & \\
\hline \multirow{2}{*}{ Major } & Clothing \& textiles & $78(76.5)$ & $73(65.8)$ & \multirow{2}{*}{2.952} \\
\hline & etc. & $24(23.5)$ & $38(34.2)$ & \\
\hline & Total & $102(47.9)$ & $111(52.1)$ & \\
\hline
\end{tabular}


Table 6. Usability of 3D body scanning \& avatar

\begin{tabular}{|c|c|c|c|c|c|c|c|c|}
\hline \multirow{2}{*}{ Category } & \multirow{2}{*}{ Variable } & \multicolumn{2}{|c|}{$\operatorname{Total}(\mathrm{n}=213)$} & \multicolumn{2}{|c|}{ Male $(n=43)$} & \multicolumn{2}{|c|}{ Female $(\mathrm{n}=170)$} & \multirow{2}{*}{ t-value } \\
\hline & & M & S.D. & $\mathrm{M}$ & S.D. & M & S.D. & \\
\hline \multirow{5}{*}{$\begin{array}{l}\text { Fashion } \\
\text { coordination } \\
\text { system }\end{array}$} & Physical appearance of information & 4.3 & .76 & 4.2 & .87 & 4.4 & .72 & -1.429 \\
\hline & Exact dimensions of information & 4.2 & .86 & 4.2 & .95 & 4.2 & .84 & -.253 \\
\hline & Convenience(measuring the dressed state) & 4.1 & .90 & 4.1 & .93 & 4.1 & .90 & -.047 \\
\hline & Variety of styling \& coordination of information & 4.1 & .85 & 4.2 & .84 & 4.1 & .85 & .800 \\
\hline & Styling coordination of information & 4.0 & .92 & 4.0 & 1.0 & 4.0 & .90 & -.072 \\
\hline \multirow{4}{*}{$\begin{array}{l}\text { 3D avatar } \\
\text { application }\end{array}$} & To utilize the on-line shopping & 4.2 & .79 & 4.1 & .79 & 4.2 & .80 & -.314 \\
\hline & To utilize the off-line shopping & 4.0 & .85 & 4.1 & .83 & 4.0 & .85 & .849 \\
\hline & To purchase product & 4.2 & .79 & 4.1 & .91 & 4.2 & .76 & -.271 \\
\hline & Utilization of recognition & 3.5 & .94 & 3.4 & .96 & 3.5 & .94 & -.798 \\
\hline \multirow{5}{*}{$\begin{array}{l}\text { 3D body } \\
\text { scanning } \\
\text { process }\end{array}$} & Scanning experience is interesting & 4.4 & .79 & 4.2 & .84 & 4.4 & .77 & -1.119 \\
\hline & Scanning process is convenient & 4.2 & .84 & 4.1 & .96 & 4.2 & .81 & -.699 \\
\hline & Scanning time is appropriate & 4.1 & .85 & 4.1 & .89 & 4.1 & .84 & .231 \\
\hline & To recommend the $3 \mathrm{D}$ fashion body scanning & 4.0 & .77 & 4.0 & .93 & 4.0 & .73 & -.353 \\
\hline & Appropriateness of body measurement contents and items & 4.0 & .87 & 4.0 & .96 & 4.0 & .84 & -.786 \\
\hline
\end{tabular}

5-point Likert-type : 1(strongly disagree) to 5(strongly agree)

vey did not show significant difference according to gender. And the significant difference didn't appear about awareness according to the major (Table 5).

Next, a questionnaire survey was conducted with a 5-point likert-type scale ranging 1 (strongly disagree) to 5 (strongly agree) concerning ' $3 \mathrm{D}$ body scanning $\&$ fashion avatar experience' in Table 6. The result of the survey did not show significant difference according to gender, that is, both male and female all showed a positive attitude about it.

In addition, about the question regarding the 'Fashion coordination system of 3D body scanning', the response indicated over 4.2 among 5 so that they can use 'Physical appearance' \& 'exact dimensions of information'. About the question regarding the 'Convenience of measuring the dressed state and 3D virtual fitting (4.1)' and 'Styling coordination (4.1)', the results showed overall positive attitude (4.2) about that, with the item of 'Contents of avatar application', the respondents were thought to be likely to utilize the 'On-line (4.2)' shopping rather than the 'Off-line (4.0)' shopping.

Lastly, about ' $3 \mathrm{D}$ body scanning process', the result indicated overall positive response by answering as follows: '3D body scanning experience is interesting (4.4)', '3D body scanning process is convenient (4.2)', '3D body scanning time is appropriate (4.1)', 'They willing to recommend the 3D fashion body scanning (4.0)', 'Appropriateness of body measurement contents and items (4.0)'.

After generating an individual avatar by applying the 3D body scanning data, questions were asked on the necessary services for
Table 7. Needed services to 3D body scanning service unit: $\mathrm{n}(\%)$

\begin{tabular}{lcccc}
\hline \multicolumn{1}{c}{ Variable } & Total & Male & Female & $\chi^{2}$ \\
\hline Accuracy of size & $84(39.4)$ & $16(37.2)$ & $68(40.0)$ & \\
Adaptedness of avatar & $65(30.5)$ & $9(20.9)$ & $56(32.9)$ & 7.096 \\
Variety of coordination & $38(17.8)$ & $8(18.6)$ & $30(17.6)$ & \\
Convenience of shopping & $26(12.2)$ & $10(23.3)$ & $16(9.4)$ & \\
\hline
\end{tabular}

styling and coordination. As a result, 39.4\% of them said they needed the 'Accuracy of size' the most, followed by 'Adaptedness of avatar' $30.5 \%$, 'Variety of coordination' $17.8 \%$ and 'Convenience of shopping' $12.2 \%$. A chi-square analysis was done according to genders but no significance difference was found between male and female (Table 7).

A questionnaire survey was conducted with a 5-point likert-type scale ranging 1 (strongly disagree) to 5 (strongly agree) concerning 'similarity of own body', 'The satisfaction with garment fitting', with scale ranging 1 (very big) to 5 (very small) concerning 'Comparing of avatar vs real me'. The male 43 persons, Female 116 persons answered in this question (Table 8).

After the perception have an experience of 3D body scanning, this question showed a positive result with reactions on 'Similarity of own body (3.6)' \& 'The satisfaction with garment fitting (3.8)', and the results of the study's respondents showed that satisfaction level still isn't high enough with 3D avatar creation by body scanning and real themselves, because 3D body scanning became operative with their clothes on. 
Table 8. Adaptedness of avatar vs real me

\begin{tabular}{|c|c|c|c|c|c|c|c|c|}
\hline \multirow{2}{*}{ Category } & \multirow{2}{*}{ Variable } & \multicolumn{2}{|c|}{ Total } & \multicolumn{2}{|c|}{$\operatorname{Male}(n=24)$} & \multicolumn{2}{|c|}{ Female(n=116) } & \multirow{2}{*}{ t-value } \\
\hline & & $\mathrm{M}$ & S.D. & $\mathrm{M}$ & S.D. & $\mathrm{M}$ & S.D. & \\
\hline \multirow{2}{*}{ Similarity } & Similarity of own body & 3.6 & .70 & 3.6 & .65 & 3.6 & .71 & .356 \\
\hline & The satisfaction with garment fitting & 3.8 & .67 & 3.8 & .48 & 3.8 & .70 & .488 \\
\hline \multirow{10}{*}{$\begin{array}{l}\text { Comparing } \\
\text { avatar vs } \\
\text { real me }\end{array}$} & Stature & 2.8 & .49 & 3.0 & .30 & 2.7 & .51 & $3.370^{* * *}$ \\
\hline & Leg length & 3.1 & .50 & 3.1 & .28 & 3.0 & .53 & .358 \\
\hline & Arm length & 3.0 & .45 & 2.9 & .41 & 3.0 & .46 & -.657 \\
\hline & Shoulder breadth & 3.1 & .47 & 3.2 & .51 & 3.1 & .46 & 1.087 \\
\hline & Bust circumference & 3.0 & .36 & 2.9 & .28 & 3.0 & .37 & -1.249 \\
\hline & Waist circumference & 2.8 & .54 & 2.9 & .28 & 2.8 & .57 & 1.687 \\
\hline & Hip circumference & 2.9 & .43 & 2.9 & .28 & 2.9 & .46 & .383 \\
\hline & Thigh circumference & 2.9 & .40 & 3.0 & .30 & 2.9 & .41 & 1.571 \\
\hline & Upper arm length & 3.0 & .37 & 2.9 & .28 & 3.0 & .38 & -.695 \\
\hline & Abdominal extension circumference & 2.8 & .52 & 2.9 & .28 & 2.8 & .55 & 1.602 \\
\hline
\end{tabular}

The sizes of 3D avatar shape and real me were compared for accuracy by separating male and female. As a result, no significant difference was found in all items excluding stature. 'leg length' and 'shoulder breadth' item were found to be 3.1, meaning smaller measurement than real me. The 'arm length' and 'bust circumference' were 3.0, signaling appropriateness in fitting. Other items including 'waist circumference' and 'abdominal extension circumference' 2.8, 'hip circumference', and 'thigh circumference' were 2.9 , which means larger measurements than real me. Male and female showed a significant difference in 'stature' item. Male said the fitting was okay and female said the fitting was larger than themselves.

\subsection{Comparing $3 D$ body scanning and direct measure-} ment
It showed 3D body scanning and direct measurement data of Table 9. The participants in the 3D body scanning experience experiment, 6 male and 45 female (51 people in total) were directly measured for their body size to perform the t-test of 3D body scan data and the direct measurement sizes. As a result, the 'shoulder breadth', 'waist circumference', 'thigh circumference', and 'abdominal extension circumstance' showed significance at $p<.001$ level. The 'arm length', and 'abdominal circumference' showed a significant difference at $p<.01$ and the 'stature' at $p<.05$. In the 3D body scan data, the averages of 'stature' and 'waist circumference' were larger than the direct measurements. The averages of 'arm length', 'shoulder breadth', 'thigh circumference', 'abdominal extension circumference', etc were smaller than the direct measurements. Also, the standard deviation of 3D body scan data were found to be bigger in circumference items, indicating the

Table 9. Measurements data by using 3D body scanner and direct method

$\mathrm{n}=51$, unit: $\mathrm{cm}$

\begin{tabular}{|c|c|c|c|c|c|}
\hline \multirow{2}{*}{ Items } & \multicolumn{2}{|c|}{ 3D body scanning } & \multicolumn{2}{|c|}{ Direct measurements } & \multirow{2}{*}{ t-value } \\
\hline & M & S.D. & M & S.D. & \\
\hline Stature & 166.2 & 6.5 & 163.6 & 6.4 & $2.043^{*}$ \\
\hline Leg length & 75.0 & 3.9 & 74.3 & 4.4 & .910 \\
\hline Arm length & 54.7 & 3.6 & 56.7 & 3.0 & $-3.002^{* *}$ \\
\hline Shoulder breadth & 35.4 & 3.7 & 38.4 & 2.4 & $-4.890^{* * *}$ \\
\hline Bust circumference & 82.1 & 7.4 & 84.0 & 6.4 & -1.370 \\
\hline Waist circumference & 75.7 & 6.6 & 67.7 & 5.1 & $6.890^{* * *}$ \\
\hline Hip circumference & 94.1 & 5.4 & 92.3 & 4.7 & 1.842 \\
\hline Thigh circumference & 45.5 & 4.8 & 53.1 & 3.9 & $-8.810^{* * *}$ \\
\hline Abdominal extension circumference & 81.0 & 5.6 & 84.7 & 5.6 & $-3.383^{* *}$ \\
\hline
\end{tabular}

${ }^{*} p<.05^{* *} p<.01{ }^{* * *} p<.001$ 
possibility of inconsistent measurement. Possibly problems in this relation will need to be addressed.

\section{Conclusion}

This research seeks to understand customer satisfaction with virtual fitting based on 3D body scanner and avatars as well as differences between such avatars and real me. To this end, this research examined Korean male and female college students to perform the 3D body scanning, avatar generation and surveys. By comparing the 3D body scan data with direct measurements, the author of this research tried to identify any difference between the $3 \mathrm{D}$ body scan data-based my avatar and real me in the virtual dress fitting system.

Survey was performed after they experienced 3D body scanning and avatar fitting. The results are summarized as follows:

The question on the level of customer awareness on 3D body scanner found that the majority of both genders did not know about it, indicating a lower usability of incorporating such an IT technology into the fashion industry.

The question in the 3D body scanning and avatar found affirmative attitude from both genders. Of them, the item that such a fashion coordination system provides information on one's physical appearances and uses accurate sizes gained a positive outcome of 4.2 point. The respondent said the system was convenience as they did not have to actually change clothes while using the virtual scan data of clothes fitting. They showed a positive result of 4.1 point for the variety of styling and coordination. These findings indicate the participants had a higher interest in body scanning and avatar. The question on the application of 3D avatar gained at least 4.0 points for most of its sub-items, suggesting that people had the intention to use the virtual system in their online and offline shopping with the thought that the system was helpful in their dress purchase. The question on $3 \mathrm{D}$ scanning procedures found that the participants thought the scanning experience interesting and convenient while requiring only appropriate amount of time. The survey question on the most-needed service aspect in the $3 \mathrm{D}$ body scanning found that accuracy of size $>$ adaptedness of avatar $>$ variety of coordination $>$ convenience of shopping in order, indicating the largest demand for the accuracy of size. This seems because customers wanted the avatar identical to real me. And as they had to decide dress purchase just by looking at their avatars wearing a cloth, they are deemed to regard the item most importantly. Their satisfaction levels on the 3D avatars' similarity with own body (3.6) and garment fitting (3.8) were positive but not very high, indicating the need for further technological improvement in expressing the avatars identical to customers' own body as much as possible.

Next, the t-test results of the 3D scan data and direct measurements showed significant differences in 6 items (stature, arm length, shoulder breadth, waist circumference, thigh circumference, abdominal extension circumference) out of the total of 9. As for the $3 \mathrm{D}$ body scanning that measured body sizes while wearing a cloth, more research is necessary for the accuracy of sizes. And the avatars produced based on such data, too, may be less similar to the own bodies, possibly causing customer dissatisfaction.

In this research 3D body scanning process, the participants were requested to take off their overcoats and metal goods (cards, keys, mobile phones, etc.) including accessories (necklace, rings, bracelets, watches, etc.). But metal accessories attached on clothes (metal zipper, rivets, foils, etc.) disturbed the scanning to cause inaccurate measuring results in some cases. In this sense, if the scanning is to be practices in actual dress shops, some customers may need to take off their clothes. More convenient scanning method will need to be developed for better application to the fashion industry.

Some of the 3D body scanning data gained without cloth taking off and direct measurement data items showed significant differences. Thus, further technology development is required to narrow these gaps in using these data to make avatars in order to provide more accurate virtual fitting simulation service to customers. With more accurate data, the 3D avatars should be able to deliver more accurate dress fitting to customers for their better-informed purchase decision.

The advancement of 3D human measuring scanning system is expected to introduce more convenient consumption patterns by offering customers virtual experience of wearing a desired cloth actually in physical stores or online stores. And the generation of avatars, if realized more accurately as real me, is expected to help facilitate related apparel industry.

This research investigated college students of clothing department so is limited in the frequency, gender, age distribution in the sample. Generalization of the research findings should be carefully considered. Follow up studies, therefore, will need to study more diversified regions, majors, academic backgrounds, etc. to look into various fashion consumers with different body types and measurements for more in-depth 3D body scanning study and preference on and satisfaction with the avatars in the virtual fitting service.

\section{Acknowledgement}

This research was supported in 2015 by the MOE (The Ministry of Education), Republic of Korea, under the BK21 plus project (S15HR15D0801) supervised by the NRF (National Research 
Foundation of Korea).

\section{References}

'3D Scanners'. (2014). 3D Systems. Retrieved September 1, 2014, from http://www.rapidform.com/ko/3d-scanners-3/

'3D Scanning Technical Information'. (2012). 3D Scan Company. Retrieved September 1, 2014, from http://www.3dscanco.com/ about/3d-scanning/index.cfm

'About the Body Scanner'. (2011). Cornell University College of Human Ecology. Retrieved September 1, 2014, from http:// www.bodyscan.human.cornell.edu/scene60df.html

Choi, E. H., \& Do, W. H. (2014). Consumer satisfaction with virtual avatar and garment by $3 \mathrm{D}$ body scan data. Proceedings of The Society of Fashion \& Textile Industry, International conference, Manila, Philippines, pp. 81-82.

Do, W. H. (2010). The comparison of user preference on domestic versus a foreign 3D virtual try-on system. Journal of the Korean Society of Clothing and Textiles, 34(7), 1184-1196.

$i$-Fashion Biz Center. (2014). i-Fashion Biz Center. Retrieved April 18, 2014, from https://www.avatarzone.kr/pages/business

Lim, H. S. (2012). Analysis of utilization of virtual try on simulation and consumers' preference in apparel online shopping. Fashion \& Textile Research Journal, 14(1), 83-89. doi:10.5805/KSCI.2012.14.1.083

Park, C. K., \& Kim, S. M. (2004). Fiber technology and industry. The Korean Fiber Society, 8(1), 30-41.

Pack, K. J. (2006). Body measurement and fit analysis using $3 D$ body scanner. Unpublished doctoral dissertation, Pusan National University, Busan.

Yoon, J. Y. (2011). (A) study on 3D virtual fitting system using avatar fashion. Unpublished master's thesis, Hong-Ik University, Seoul.

(Received 30 December 2014; 1st Revised 5 March 2015; 2nd Revised 15 April 2015; Accepted 19 May 2015)

(C) 2015 (by) the authors. This article is an open access article distributed under the terms and conditions of the Creative Commons Attribution license (http://creativecommons.org/licenses/by/3.0/), which permits unrestricted use, distribution, and reproduction in any medium, provided the original work is properly cited. 